\title{
Organizational Commitment ditinjau dari Psychological Ownership pada Karyawan PT Capella Dinamik Nusantara Medan
}

\author{
Jovian Julius, Diny Atrizka, Rianda Elvinawanty \\ Universitas Prima Indonesia \\ Email: jovianjulius03@gmail.com
}

\begin{abstract}
The purpose of this study is to find out about the relationship between organizational commitment and psychological ownership. The hypothesis that the researchers propose in this study is that there is a positive and significant relationship between organizational commitment and psychological ownership, assuming that the higher the organizational commitment, the higher the psychological ownership and conversely. The selection of participants for this study used a sampling method, namely purposive sampling. The sample of this research is 141 employees who are permanent employees who have more than 1 year of service at PT. Capella Dinamik Nusantara Medan. Data collected by researchers, comes from the collection results with a scale that has been prepared with reference to the theoretical dimensions used by researchers to measure organizational commitment and psychological ownership. The correlation coefficient obtained was $0.613(p<0.05)$. These results indicate that there is a positive and significant relationship between organizational commitment and psychological ownership. The results of this study contribute to the Industrial \& Organizational Psychology sector in particular to increase employee commitment.
\end{abstract}

Keywords: employee, organizational commitment, psychological ownership

\begin{abstract}
Abstrak
Tujuan penelitian ini ialah untuk mengetahui tentang adanya korelasi antara organizational commitment dan psychological ownership. Adapun hipotesis yang peneliti ajukan dalam penelitian ini adalah terdapat hubungan positif antara organizational commitment dan psychological ownership, dengan asumsi bahwa semakin tinggi organizational commitment, semakin tinggi pula psychological ownership dan sebaliknya. Pemilihan partisipan untuk penelitian ini menggunakan metode pengambilan sampel yaitu purposive sampling. Adapun sampel dari penelitian ini ialah 141 karyawan yang merupakan karyawan tetap yang memiliki masa kerja lebih dari 1 tahun di PT. Capella Dinamik Nusantara Medan. Data yang dikumpulkan oleh peneliti, berasal dari hasil pengumpulan dengan skala yang telah disusun dengan mengacu pada dimensi teori yang digunakan peneliti untuk mengukur Organizational commitment dan psychological ownership. Adapun Metode dalam analisis data tersebut dalam penelitian ini menggunakan metode analisi Pearson Product Moment Correlation yang diolah melalui bantuan program SPSS 17.00 for Windows. Koefisien korelasi yang didapatkan sebesar 0,613 ( $<<0,05)$. Hasil tersebut menunjukkan terdap hubungan yang positif dan juga signifikan antara organizational commitment dan psychological ownership. Hasil penelitian ini berkontribusi pada sektor Psikologi Industri \& Organisasi khususnya untuk meningkatkan komitmen karyawan.
\end{abstract}

Kata kunci: karyawan, komitmen organisasi, kepemilikan psikologis

\section{Pendahuluan}

Organisasi merupakan kesatuan (susunan dan sebagainya) yang terdiri atas bagian-bagian (orang dan sebagainya) dalam perkumpulan dan sebagainya untuk tujuan tertentu. Di dalam menjalankan kegiatannya, organisasi membutuhkan sumber daya/asset untuk mencapai tujuan yang ingin dicapai. Sumber daya/asset tersebut terbagi dua, yaitu tangible asset dan intangible asset. Tangible asset dapat berupa modal uang, gedung, bahan baku, produk, saham, tanah, kendaraan, dan asset kasat mata. Sedangkan intangible asset dapat berupa bakat, keahlian, sikap, jaringan, serta pengetahuan (Soebari, 2008). Di dalam pengelolaannya, kedua sumber daya/asset tersebut harus dapat dikelola bersama - sama agar dapat memberikan nilai bagi organisasi dalam menjalankan kegiatannya. Manusia sebagai sumber daya yang menjalankan organisasi mempunyai peran yang sangat penting dalam mencapai target organisasi. Hal ini disebabkan karena manusia memiliki intangible asset yaitu bakat, keahlian, pengetahuan dan sikap yang sangat penting untuk mengelola tangible asset.Sumber Daya Manusia berkualitas sangat dibutuhkan oleh organisasi karena manusia menciptakan sistem didalam menjalankan organisasinya dengan menggunakan pengetahuan dan keahlian yang dimilikinya. Sehingga kualitas dari sumber daya manusia yang dimiliki oleh organisasi akan sangat berpengaruh pada hasil yang akan dicapai oleh organisasi. Oleh karena itu, organisasi perlu mengelola dan mengembangkan potensi serta kesejahteraan karyawan didalamnya agar karyawan dapat memberikan kinerja dan produktifitas yang 
maksimal dalam mendukung pencapaian target organisasi. Hal ini penting untuk diperhatikan oleh organisasi karena semakin berkembangnya jaman, peningkatan keahlian dan pengetahuan karyawan sangat penting agar karyawan dapat terus memberikan kontribusi maksimal sehingga produk atau jasa yang dikeluarkan oleh perusahaan dapat terus bersaing dan lebih unggul dibandingkan dengan produk atau jasa yang dikeluarkan oleh kompetitor. Selain meningkatkan keahlian, perusahaan juga perlu menjaga kondisi psikologis karyawan, karena dengan kondisi psikologis yang baik mendorong karyawan untuk memberikan kinerja yang terbaik. Hal ini juga akan menentukan keberlangsungan hidup karyawan di perusahaan. Apabila perusahaan tidak dapat menjaga kondisi psikologis karyawan maka karyawan akan cenderung memilih meninggalkan perusahaan ataupun melakukan tindakan - tindakan yang menyimpang dari kewajiban si karyawan. Tindakan - tindakan yang menyimpang tersebut terjadi pada salah satu perusahaan di Indonesia yaitu Tokopedia, dalam menyambut ulang tahun Tokopedia yang ke - 9 dengan membuat gelaran Flash Sale (pemberian potongan harga dari produk yang ditawarkan dalam waktu singkat) setelah dilakukannya audit internal perusahaan, didapati beberapa oknum karyawan yang terbukti melakukan pelanggaran transaksi terhadap beberapa beberapa produk dari kampanye promosi Tokopedia. Menanggapi kasus tersebut dari pihak perusahaan yaitu Tokopedia telah melakukan pemutusan hubungan kerja dengan oknum karyawan tersebut. CEO Tokopedia, William Tanuwijaya mengungkapkan bahwa di Tokopedia integritas adalah hal yang penting, beliau menyampaikan memang secara jumlah kecil sekali tindakan yang dilakukan oleh oknum tersebut. Tetapi bagi perusahaan ini bukan persoalan seberapa kecil pelanggarannya, melainkan kegagalan integritas dalam menjaga titipan kepercayaan yang telah diberikan oleh perusahaan yaitu Tokopedia. (www.kompas.com)

Berdasarkan hasil observasi pada PT Capella Dinamik Nusantara terkhusus untuk karyawan di kantor pusat Medan, didapatkan masih kurangnya keberpihakan terhadap tujuan dan nilai perusahaan yang dapat dilihat dari perbuatan-perbuatan yang tidak sesuai dengan peraturan perusahaan seperti : karyawan yang mangkir/absen, intensitas keterlambatan yang sering terjadi, adanya karyawan yang menganggap permasalahan yang dihadapi oleh perusahaan bukan merupakan masalahnya serta perbuatan-perbuatan lain yang dinilai kurang sesuai dengan aturan perusahaan baik sengaja ataupun tidak disengaja serta meningkatnya jumlah karyawan yang berhenti terutama di kantor pusat Medan setiap tahunnya.

Kondisi di atas sesuai dengan konsep organizational commitment yang disampaikan oleh Greenberg (dalam Sagala, 2013) adalah sebagai sikap konsisten individu terhadap organisasi di mana mereka bekarya dan memiliki kecenderungan dalam mempertahankan keanggotaan mereka dalam organisasi. Organizational commitment menurut pendapat Mathis dan Jackson (dalam Utaminingsih, 2014) merupakan derajat keyakinan serta menerima apa yang menjadi harapan dan tujuan organisasi serta mengambil keputusan untuk mempertahankan keanggotaannya dalam organisasi tersebut.

Sopiah (2008) berpendapat bahwa tinggi rendahnya komitmen karyawan akan berdampak terhadap karyawan itu pribadi serta terhadap organisasi. Dampak organizational commitment terhadap karyawan itu sendiri, salah satunya dalam konteks pengembangan dan peningkatkan karir dari karyawan tersebut di dalam organisasi/perusahaan dan dampak organizational commitment terhadap organisasi itu sendiri adalah timbulnya kinerja organisasi yang lebih efektif dan efisien, intensitas karyawan yang mangkir/absen serta keterlambatan yang lebih minim, serta memilik rasa loyalitas yang lebih tinggi terutama dalam mencapai target perusahaan dan lain lain.

Hackett dan Gunion (dalam Sopiah, 2008) menyampaikan bahwa umumnya karyawan dengan organizational commitment yang tinggi akan memberikan dampak terhadap karyawan tersebut, yaitu memiliki tingkat kepuasaan yang lebih tinggi terhadap pekerjaanya dan memiliki intensitas mangkir/absen serta keterlambatan yang lebih minim. Ahli lain seperti Robbins dan Judge (dalam Sopiah, 2008), juga menjelaskan bahwa karyawan yang memiliki organizational commitment yang tergolong tinggi cenderung menjaga dan mempertahankan keanggotaannya dalam organisasi tersebut. Menurut Judge dan Watanabe (dalam Sopiah, 2008) karyawan dengan organizational commitment tinggi ialah mereka yang cenderung merasa lebih puas dalam menjalani kehidupan mereka secara keseluruhan.

Salah satu faktor yang dapat memberikan pengaruh terhadap organizational commitment adalah psychological ownership, penelitian yang dilakukan oleh Avey, dkk (2009) menunjukan adanya pengaruh dari psychological ownership terhadap organizational commitment. Penelitian ini mendapatkan bahwa semakin karyawan memiliki rasa memiliki di dalam organisasi/perusahaan maka karyawan juga akan memihak visi \& misi dari organisasi/perusahaan tersebut dan memiliki keinginan 
untuk bertahan diorganisasi tersebut. Karyawan yang berkomitmen terhadap organisasinya cenderung mematuhi peraturan perusahaan dan memberikan kinerja terbaik untuk mendukung pencapaian target perusahaan. Hal ini terlihat dari perilakunya yang proaktif dalam mengembangkan dan meningkatkan kinerja perusahaan serta mencari solusi terhadap permasalahan yang terjadi di perusahaan.

Pierce dan Jussila (2014), menjelaskan psychological ownership sebagai salah satu dari beberapa kondisi yang menggambarkan hubungan psikologis individu yang terbentuk dengan pekerjaan dan organisasi mereka. Setiap Kondisi dapat dilihat sebagai kelekatan psikologis yang menghubungkan dan mengikat individu ke pekerjaan yang mereka lakukan (yaitu, pekerjaan mereka) dan ke organisasi tempat mereka bekerja. Menurut Dyne dan Pierce (dalam Olkcers, dkk, 2017), psychological ownership adalah sebuah perasaan posesif serta rasa mengontrol atas benda-benda yang dimiliki secara psikologis. Berdasarkan fenomena yang sudah diuraikan dan dijelaskan diatas peneliti terdorong dalam melaksanakan penelitian yang berjudul "Organizational Commitment ditinjau dari Psychological Ownership dari Karyawan PT Capella Dinamik Nusantara Medan”. Tujuan yang ingin peneliti capai dari penelitian ini adalah untuk melihat adanya korelasi antara psychological ownership dengan organizational commitment. Adapun manfaat praktis dalam penelitian ini bagi karyawan adalah diharapkan karyawan yang memiliki komitmen terhadap organisasi yang tinggi akan memiliki motivasi yang tinggi untuk memberikan yang terbaik sehingga memberikan kinerja yang terbaiknya. Karyawan yang memberikan kinerja terbaiknya maka semua imbalan secara material ataupun peningkatan karir dari perusahaaan akan mengikutinya. Sedangkan manfaat praktis bagi organisasi adalah meningkatkan produktifitas perusahaan karena memiliki karyawan yang berkomitmen tinggi dan perusahaan memiliki kader-kader yang akan meneruskan eksistensi perusahaan, meminimalkan biaya rekrutmen serta training karyawan baru.

Hipotesis dalam penelitian ini ialah psychological ownership dengan organizational commitment memiliki hubungan yang positif serta signifikan. Peneliti mengasumsikan bahwa jika semakin tinggi psychological ownership yang dimiliki oleh karyawan dalam suatu organisasi maka semakin tinggi juga organizational commitment dari karyawan tersebut. Demikian pula sebaliknya, semakin rendah psychological ownership yang dimiliki oleh karyawan maka semakin rendah pula organizational commitment yang dimilikinya.

\section{Metode Penelitian}

Adapun dalam penelitian ini organizational commitment merupakan variabel terikat (dependent variable) dan psychological ownership, merupakan variabel bebas (independent variable).

Populasi penelitian ini merupakan karyawan dari PT. Capella Dinamik Nusantara Medan sebanyak 224 karyawan. Berdasarkan pendapat Sugiyono (2016) sampel ialah bagian dari populasi yang memiliki jumlah serta karakteristik/kriteria. Untuk menentukan jumlah sampel digunakan tabel Isaac dan Michael yang memiliki dengan nilai signifikansi sebesar 5\% dengan populasi karyawan/karyawati sebanyak 224 orang jumlah sampel menjadi 141 orang. Pemilihan partisipan diambil berdasarkan teknik sampling yaitu : purposive sampling dengan kriteria merupakan karyawan PT. Capella Dinamik Nusantara Medan yang memiliki masa kerja lebih dari 1 tahun dan berstatus sebagai karyawan tetap.

Penelitian ini menggunakan Instrumen pengambilan data berupa skala pengukuran untuk mengukur organizational commitment dan psychological ownership. Skala Organizational Commitment peneliti kembangkan berdasarkan dimensi-dimensi organizational commitment yang dikemukakan oleh Meyer \& Allen (dalam Kusumaputri, 2015) dijelaskan bahwa organizational commitment menggunakan model tiga dimensi yang meliputi dimensi komitmen afektif yang merepresentasikan keterlibatan emosional individu dalam organisasi, dimensi komitmen berkelanjutan (continuance) yang merepresentasikan kesadaran individu dengan keterikatan instrumental, dimensi komitmen normatif mengambarkan anggota yang bertahan dalam organisasi karena landasan keharusan. Pada Skala Organizational Commitment yang disusun oleh peneliti terdapat total 45 item. Dari setiap dimensi tersebut disusun dengan 15 item yang memiliki komposisi 8 item favourable serta 7 item unfavourable.

Skala Psychological Ownership peneliti kembangkan berdasarkan dimensi-dimensi psychological ownership yang dipaparkan oleh Olckers (dalam Coetzee, 2014) yang meliputi self-efficacy (efikasi diri), self-identity (identitas diri), belongingness (rasa memiliki), accountability (akuntabilitas), autonomy, responsibility (tanggung jawab), territoriality. Pada Skala Psychological Ownership yang 
disusun oleh peneliti terdapat total 49 item. Dari setiap dimensi tersebut disusun dengan 7 item yang memiliki komposisi 4 item favourable serta 3 item unfavourable.

Selanjutnya peneliti melaksanakan try out menggunakan skala yang sudah disusun terhadap 61 karyawan yang bekerja di PT. Star Auto Multilink Medan yang memang memiliki kesamaan dengan karakteristik dari subjek penelitian. Hasil tryout digunakan untuk melihat validity atau sejauh mana ketepatan dan kecermatan suatu alat ukur yang telah peneliti susun. Berdasarkan pendapat Azwar (2012), suatu tes atau instrumen pengukur dapat dikatakan mempunyai validitas yang tinggi apabila alat tersebut menjalankan fungsi ukurnya atau memberikan hasil ukur yang sesuai dengan maksud dilakukannya pengukuran tersebut. Uji validitas dilakukan terhadap kedua skala yang telah disusun. Pada item Skala Organizational Commitment memperlihatkan rentang nilai $0.311-0.564$ dan ada 16 item yang gugur dikarenakan memiliki nilai daya diskriminasi item dibawah dari taraf 0.3 . Sehingga jumlah item yang dapat dipakai untuk penelitian ini berjumlah total 29 item yang digunakan untuk mengukur organizational commitment pada setiap subjek dari penelitian ini. Sedangkan uji validitas yang dilakukan terhadap item Skala Psychological Ownership memperlihatkan rentang nilai 0.3340.665 dan ada sebanyak 15 item yang gugur dikarenakan memiliki nilai daya diskriminasi item dibawah dari taraf 0.3. Sehingga jumlah item yang dapat dipakai untuk penelitian ini berjumlah total 34 item yang akan digunakan untuk mengukur psychological ownership pada setiap subjek dari penelitian ini. Selanjutnya peneliti menyebarkan skala penelitian terhadap 141 karyawan yang merupakan subjek penelitian. Peneliti kemudian mengumpulkan data dan mengolah data serta melakukan uji hipotesis dengan metode analisa data yaitu korelasi Product Moment Pearson.

\section{Hasil dan Pembahasan}

Adapun untuk proses analisis data yang dilakukan oleh peneliti dalam penelitian ini menggunakan bantuan aplikasi SPSS 17 for Windows. Peneliti melakukan uji asumsi yang berupa uji normalitas data serta uji linieritas.

Tabel 1. Hasil Uji Normalitas

\begin{tabular}{cccccc} 
Variabel & SD & K-SZ & Sig. & P & Keterangan \\
\hline $\begin{array}{c}\text { Organizational } \\
\text { commitment }\end{array}$ & 7.962 & 1.006 & 0.726 & $\mathrm{P}>0,05$ & Sebaran normal \\
\hline Psychological ownership & 10.278 & 1.209 & 0.457 & $\mathrm{P}>0,05$ & Sebaran normal
\end{tabular}

Untuk mengetahui apakah setiap variabel penelitian sudah memiliki penyebaran nilai yang normal atau tidak, maka peneliti melakukan uji normalitas terhadap data yang telah dikumpulkan. Uji normalitas sebaran ini menggunakan uji Kolmogorov Smirnov Test. Data dapat dikatakan berdistribusi normal jika nilai signifikansi di atas dari nilai 0.05 dan sebaliknya data dikatakan tidak berdistribusi secara normal jika nilai signifikansi di bawah dari nilai 0.05 (Priyatno, 2011). Berdasarkan hasil uji normalitas sebaran yang dilakukan sebagaimana terdapat pada Tabel 1 terhadap variabel organizational commitment diperoleh hasil signifikansi uji satu arah dari variabel organizational commitment yaitu 0.132 ( $p>0.05$ ), dimana dari hasil tersebut menunjukan variabel organizational commitment sudah terdistribusi secara normal. Untuk variabel lainnya yaitu psychological ownership juga dilakukan uji normalitas sebaran dan diperoleh hasil signifikansi uji satu arah dari variabel psychological ownership yaitu 0.054 (p>0.05), dimana dari hasil tersebut menunjukan variabel psychological ownership sudah terdistribusi secara normal. Setelah dilakukan uji normalitas, peneliti menjalankan tahapan uji linearitas untuk mendapati apakah variabel psychological ownership dan Organizational commitment mempunyai hubungan yang linear atau tidak. Dari hasil pengolahan data yang peneliti peroleh, diketahui nilai signifikansi yang didapatkan yaitu 0.000 dimana nilai tersebut masih dibawah dari dari taraf 0.05 sehingga kedua variabel dalam penelitian ini dapat dikatakan memiliki hubungan yang linear. Selanjutnya peneliti melakukan pengolahan data untuk mendapatkan hasil analisa korelasi Product Moment.

Tabel 2. Korelasi antara Psychological ownership dengan Organizational commitment

\begin{tabular}{ccc} 
Variabel & Pearson Correlation & Signifikansi (p) \\
\hline $\begin{array}{c}\text { Psychological ownership } \\
\text { Organizational commitment }\end{array}$ & 0.613 & 0.000 \\
\hline
\end{tabular}

Psyche 165 Journal Terakredetasi Sinta 5 
Berdasarkan hasil uji hipotesis korelasi antara psychological ownership dan organizational commitment yang dianalisa menggunakan teknik Pearson Product Moment Correlation sebagaimana ada pada tabel 2 dapat disimpulkan bahwa positif yang kuat dan signifikan antara psychological ownership dengan organizational commitment $(\mathrm{r}=0.613, \mathrm{p}=0.000<0.05)$. Hasil uji hipotesis menunjukkan korelasi yang diperoleh positif dan signifikan sehingga korelasi tersebut dikategorikan memiliki hubungan yang kuat (Priyatno, 2011). Dengan berdasarkan dari hasil uji hipotesis yang didapatkan, hipotesis yang diusulkan oleh peneliti dapat diterima yaitu adanya hubungan positif antara psychological ownership dengan organizational commitment pada karyawan di PT. Capella Dinamik Nusantara Medan.

\begin{tabular}{|c|c|c|c|c|}
\hline \multicolumn{5}{|c|}{ Tabel 3. Sumbangan Efektif } \\
\hline Model & $R$ & $\begin{array}{c}\mathrm{R} \\
\text { Square }\end{array}$ & $\begin{array}{l}\text { Adjusted R } \\
\text { Square }\end{array}$ & $\begin{array}{l}\text { Std. Error of the } \\
\text { Estimate }\end{array}$ \\
\hline 1 & 0.613 & 0.376 & 0.748 & 0.560 \\
\hline
\end{tabular}

Selanjutnya peneliti menguji besarnya hasil sumbangan efektif dalam penelitian ini, berdasarkan tabel 3 dapat disimpulkan bahwa adanya sumbangan efektif sebesar 37.6 persen organizational commitment dalam memengaruhi psychological ownership dengan koefisien determinasi $\left(\mathrm{R}^{2}\right)$ sebesar 0.376 dan variabel lain yang tidak dikaji pada penelitian ini memengaruhi sebesar 62.4 persen.

Peneliti kemudian mengkategorisasi data penelitian yang dikumpulkan sehingga diketahui bahwa tidak terdapat karyawan yang dikategorikan memiliki psychological ownership rendah, terdapat 78 karyawan (55.32 persen) yang dikategorikan memiliki psychological ownership sedang, dan terdapat 63 karyawan (44.68 persen) yang dikategorikan memiliki psychological ownership tinggi. Dari hasil pengkategorian di atas peneliti menyimpulkan rata-rata dari karyawan yang merupakan responden dalam penelitian ini memiliki psychological ownership sedang. Hal tersebut dapat dilihat dari adanya hubungan sosial yang positif antar karyawan seperti perilaku saling menghormati antar anggota, komunikasi yang baik dan terbuka serta adanya organisasi Ikcadin (Ikatan karyawan Capella Dinamik Nusantara). Hal ini juga selaras dengan pernyataan dari beberapa karyawan berdasarkan interview karyawan mengaku bahwa perusahaan memiliki lingkungan kerja yang nyaman serta kekeluargaan yang erat. Perilaku ini sesuai dengan dimensi pada psychological ownership yaitu dimensi belongingness (rasa memiliki) dan dimensi territoriality.

Berdasarkan kategori pada variabel organizational commitment yang dikategorisasi oleh peneliti diketahui bahwa terdapat hanya 1 karyawan ( 0.01 persen) yang dikategorikan memiliki organizational commitment rendah, terdapat 122 karyawan (86.52 persen) yang dikategorikan memiliki organizational commitment sedang, dan terdapat 18 karyawan (12.77 persen) yang dikategorikan memiliki organizational commitment tinggi. Dari hasil pengkategorian di atas peneliti menyimpulkan rata-rata karyawan yang merupakan responden dalam penelitian ini memiliki organizational commitment sedang. Hal ini dapat dilihat dari kondisi absensi dari karyawan yang masih tergolong baik, walaupun ada beberapa karyawan yang mendapat himbauan dari atasan karena keterlambatan tetapi setelah diberikan arahan masih dapat menunjukan perubahan yang cukup baik dan jarang sekali ada yang sampai diberikan sanksi pemotongan insentif terhadap karyawan tersebut. Karyawan mengaku senang bekerja di perusahaan karena adanya pengembangan diri seperti diselenggarakannya acara training dan kegiatan pengembangan diri dan kompetensi lainnya, namun terkadang merasa jenuh dengan rutinitas dari pekerjaan. Perilaku ini sesuai dengan dimensi pada organizational commitment yaitu dimensi komitmen afektif.

Senada dengan penelitian oleh ahli lain yaitu Dyne dan Pierce (2004) terhadap 409 responden karyawan yang bekerja dari beragam unit di Amerika Serikat bagian tenggara pada tahun 2004 dengan hasil korelasi yaitu $(\mathrm{r}=0.70, \mathrm{p}<0.001)$ menunjukan korelasi yang signifikan dan positif antara psychological ownership dan organizational commitment. Jika semakin baik karyawan memiliki rasa memiliki terhadap organisasi ataupun perusahaan, maka komitmen karyawan terhadap organisasi semakin baik pula. Hal tersebut juga dibuktikan oleh Han, dkk., melalui penelitian yang dilakukannya, dimana didapatkan bahwa saat anggota dari organisasi/perusahaan menganggap dirinya penting di dalam organisasi/perusahaan, mereka akan meningkatkan partisipasi dan upaya lebih. Dalam organisasi/perusahaan tersebut akan tercipta ikatan yang membedakan antara anggota yang membedakan mereka dengan orang diluar organisasi. Ikatan inilah yang membuat anggota dari 
organisasi/perusahaan meningkatkan kelekatan secara individual dan emotional. Selain itu karyawan tersebut yang mengidentifikasi dirinya sebagai bagian dari organisasi memiliki organizational commitment yang lebih tinggi.

\section{Kesimpulan}

Berdasarkan hasil-hasil yang telah diperoleh dalam penelitian ini, maka dapat disimpulkan, ada hubungan positive antara psychological ownership dengan organizational commitment pada karyawan di PT. Capella Dinamik Nusantara Medan dengan korelasi Product Moment (r) 0,613 dengan p sebesar 0,000 maka $\mathrm{p}<0,05$, artinya semakin tinggi psychological ownership yang dirasakan oleh karyawan maka semakin tinggi organizational commitment yang dimiliki oleh karyawan terhadap perusahaan, dan sebaliknya jika semakin rendah psychological ownership yang dirasakan oleh karyawan maka semakin rendah pula organizational commitment yang dimiliki oleh karyawan terhadap perusahaan. Peneliti dapat menyimpulkan bahwa diantara variabel yang diteliti yaitu psychological ownership dan organizational commitment memiliki hubungan yang signifikan. Serta berdasarkan hasil yang didapatkan bahwa adanya sumbangan 37.6 persen dari organizational commitment terhadap psychological ownership dan variabel lain yang tidak dikaji pada penelitian ini mempengaruhi sebesar 62.4 persen.

Saran yang dapat diberikan peneliti kepada karyawan dari hasil penelitian peneliti yaitu karyawan perlu memahami apa yang menjadi visi serta misi perusahaan dan berusaha mempraktekkan core value (nilai inti) yang telah dirumuskan oleh perusahaan. Diharapkan karyawan ikut serta pada kegiatan yang dilaksanakan oleh perusahaan seperti kegiatan bakti sosial, acara ulang tahun perusahaan, gathering bersama dan acara perusahaan lainnya yang diselenggarakan oleh ikatan karyawan perusahaan untuk meningkatkan psychological ownership, sehingga karyawan dapat menumbuhkan rasa memiliki terhadap perusahaan sehingga dapat memicu semangat untuk berbuat lebih dan bertanggung jawab atas perusahaan karena dengan adanya semangat dan kemauan untuk berbuat lebih menjadi awal bagi karyawan untuk meningkatkan kinerja dan kompetensi yang dapat berujung pada kenaikan gaji ataupun promosi jabatan.

Untuk peneliti berikutnya yang tertarik untuk meneliti tentang organizational commitment dapat menentukan pengaruh dari variabel lain selain psychological ownership seperti masa kerja karyawan, gaya kepemimpinan transformasional, religiusitas, servant leadership dan faktor lain yang tidak dikaji dalam penelitian ini yang mampu memengaruhi organizational commitment.

\section{Daftar Rujukan}

[1] Avey, J. B., Avolio, B. J., Crossley, C. D. \& Luthans, F., 2009. Psychological ownership: Theoretical Extensions, Measurement, and Relation to Work Outcomes. Journal of Organizational Behavior, 30 (2), pp.173-191. doi: 10.1002/job.583

[2] Azwar, S., 2012. Penyusunan Skala Psikologi. Yogyakarta: Pustaka Belajar.

[3] Coetzee, M., 2014. Psycho-Sosial Career Meta-Capacities : Dynamics of Contemporary Career Development. New York: Springer.

[4] Dyne, L. V. \& Pierce, J. L., 2004. Psychological ownership and Feelings of Possession: Three Field Studies Predicting Employee Attitudes and Organizational Citizenship Behavior. Journal of Organizational Behavior, 25 (4), pp.439-459. doi: 10.1002/job. 249

[5] Han, T. S., Chiang, H. H. \& Chang, A., 2010. Employee Participation in Decision Making, Psychological ownership and Knowledge Sharing : Mediating Role of Organizational commitment in Taiwanese High-Tech Organizations. The International Jounal of Human Reource Management, 21 (12), pp.2218-2233. doi: $10.1080 / 09585192.2010 .509625$

[6] Kompas, 2018. Kasus Pemecatan Karyawan Tokopedia, idEA Sebut Internal Fraud Bisa Terjadi di Bisnis Apapun. [Online] (Updated 30 August 2018)

Available at : https://ekonomi.kompas.com/read/2018/08/30/075800926/kasus-pemecatan-karyawantokopedia-idea-sebut-internal-fraud-bisa-terjadi-di [Accessed 14 October 2018)

[7] Kusumaputri, E. S., 2015. Komitmen pada Perubahan Organisasi (Perubahan Organisasi dalam Perspektif Islam dan Psikologi). Yogyakarta: Deepublish.

[8] Olckers, C., Zyl, L. V. \& Vaart L. V., 2017. Theoretical Orientations and Practical Applications of Psychological ownership Academic Press. New York.

[9] Pierce, J. \& Jussila, L., 2011. Psychological ownership and the Organizational Context. USA: Edward Elgar Publishing.

[10] Priyatno, D., 2011. Buku Saku Analisis Statistik Data SPSS. Yogyakarta: MediaKom. 
[11] Sagala, H. S., 2013. Etika \& Moralitas Pendidikan, Peluang \& Tantangan. Jakarta: Kharisma Putra Utama. [12] Soebari, S. I., 2008. Pensiun Prenuer, Pensiun Sukses. Bogor: Penebar Swadaya.

[13] Sopiah. 2008., Perilaku Organisasi. Yogyakarta: Andi Offset.

[14] Sugiyono. 2016., Metode Penelitian. Bandung: Alfabeta.

[15] Utaminingsih, A. 2014., Perilaku Organisasi (Kajian Teoritik \& Empirik terhadap Budaya Organisasi, Gaya Kepemimpinan, Kepercayaan dan Komitmen). Indonesia: UB Press. 